\title{
DESIGN AND DEVELOPMENT OF NOVEL DRUG DELIVERY SYSTEM USING HERBAL MEDICINE TO TREAT ALZHEIMER'S DISEASE
}

\author{
RAMA RAO NADENDLA*, LAKSHMI SWAPNA SAI, NIHITHA SANKA, SANTHI PRIYA NAGAM \\ Department of Pharmaceutics, Chalapathi Institute of Pharmaceutical Sciences, Chalapathi Nagar, Lam, Guntur. \\ Email: santhipriyampharm@gmail.com
}

Received: 19 November 2018, Revised and Accepted: 09 March 2019

\section{ABSTRACT}

Objective: The present study was focused to design an herbal formulation for the treatment of Alzheimer's disease (AD) to develop the formulation using various techniques such as spray drying, centrifugation, and lyophilization and to conduct behavioral studies to evaluate the activity of the herbal formulation.

Methods: Formulation contains herbal extracts such as curcumin, guggul, and ashwagandha. To develop this formulation, various techniques such as spray drying, centrifugation, and lyophilization were employed along with a natural polymer chitosan in various combinations of excipient. Preformulation studies such as solubility of herbal extracts and Fourier transmission infrared spectroscopy (FT-IR) studies for compatibility of the natural polymer with herbal extracts were studied. The formulation was characterized by tests such as particle size determination using optical microscopy, surface morphological evaluation using scanning electron microscopy (SEM), and behavioral testing by Morris water maze test using diazepam-induced amnesia method.

Results: The particle size varied from $12.27 \mu$ for normal chitosan to $3.59 \mu$ for spray-dried chitosan. In the same way, the particle of normal formulation $(12.9 \mu)$ was about $4-5$ times larger than that of spray-dried formulation $(2.7 \mu)$. The SEM images showed no proper morphology for chitosan, round surface with wrinkles for spray-dried chitosan, improper structures for normal formulation, and rounded smooth surface for spray-dried formulation. Significant $\mathrm{p}$ value was shown when the spray-dried test formulation was tested using diazepam-induced amnesia method. The transfer latency was noted on the $8^{\text {th }}$ day and after $24 \mathrm{~h}$ of intraperitoneal administration of diazepam for the test group.

Conclusion: In the present research study, an attempt was made to design and develop a novel drug delivery system using herbal medicine to treat AD. FT-IR compatibility study was carried out using the selected polymer and the herbal extracts using novel spray-drying techniques; behavioral studies were also done.

Keywords: Chitosan, Spray drying, Herbal formulation, Alzheimer's.

(c) 2019 The Authors. Published by Innovare Academic Sciences Pvt Ltd. This is an open access article under the CC BY license (http://creativecommons. org/licenses/by/4. 0/) DOI: http://dx.doi.org/10.22159/ajpcr.2019.v12i4.32057

\section{INTRODUCTION}

Alzheimer's disease (AD) is an irreversible, progressive brain disorder that slowly destroys memory and thinking skills and eventually the ability to carry out the simplest tasks [1]. Loss of cognitive ability with age is considered to be a normal process whose rate and extent are very variable. AD was originally defined as presenile dementia, but now, it appears to be the same pathology underlies the dementia irrespective of the age of onset. Its prevalence rises sharply with age, from about $5 \%$ at $65-90 \%$ or more at 95 [2]. AD is associated with brain shrinkage and localized loss of neurons, mainly in the hippocampus and basal forebrain. The loss of cholinergic neurons in the hippocampus and frontal cortex is a feature of the disease and is thought to underlie the cognitive deficit and loss of short-term memory that occurs in AD.

Among the 120 active compounds currently isolated from the higher plants and widely used in modern medicine today, $80 \%$ show a positive correlation between their modern therapeutic use and the traditional use of the plants from which they are derived [3]. According to the survey, herbal therapy is said to be the most potential alternative to treat AD with minimal side effects. Risk-to-benefit ratio is also convincing as any overdosage of these phytoconstituents is not deleterious and these can be used as nutraceuticals too so that they can treat any unaddressed diseases or disorders.

Herbal constituents possess anti-inflammatory activity which helps in reducing inflammation in brain tissue of $\mathrm{AD}$ patient. Acetylcholine is the main neurotransmitter responsible for cognitive impairment. Any herbs that can elevate these levels can be used for treating AD. Ayurvedic plants such as Curcuma longa, Withania somnifera, Commiphora mukul, Ginseng, and Brahmi. Advantages of herbal medicine include reduced risk of side effects, effectiveness with chronic conditions, lower cost, and wide spread availability [4].

The present research was done using polyherbal extracts. To formulate this, a novel technique called spray drying was used to prepare the formulation. While formulating, preformulation studies were performed to formulation, surface morphology of was studied; additionally, behavioral studies were also conducted.

Spray-drying technique is a technique to generate powders by transforming the feed from a liquid state into a dried particulate form, by spraying the feed into a hot drying medium. The feed can be a solution, suspension, dispersion, or an emulsion. The solution to be dried is sprayed into a hot air stream and circulated through a chamber. The dried product may be carried out to cyclone or bag separators or may fall to the bottom of the drying chamber and be expelled through a valve.

Spray-drying process consists of various steps:

1. Atomization.

2. Spray-hot air contact.

3. Evaporation.

4. Separation. 


\section{MATERIALS AND METHODS}

\section{Animals, chemicals, and reagents}

Sprague Dawley (SD) rats of either sex, herbal extracts (C. longa, W. somnifera, and C. mukul) were obtained as a gift sample from Sunpure Extracts Pvt., Ltd., Delhi, and chitosan from Indian seafoods, glutaraldehyde, acetone, ethyl acetate, liquid paraffin, Span 80, Tween 80 , sodium sulfate, lactose, glacial acetic acid, diazepam, and donepezil. All the chemicals and reagents used were of analytical grade.

\section{Instruments}

Spray dryer (CRONIMACH), centrifuge (REMI), Fourier transmission infrared spectroscopy (FT-IR) (BRUKER), optical microscope (OLYMPUS), scanning electron microscopy (SEM) (NIKON TS 100), magnetic stirrer (REMI), mechanical stirrer (REMI), ultra probe sonicator (OSCAR), Ultra-Turrax (IKA T25), freeze dryer (iLShin), and weighing balance (SHIMADZU) were used.

\section{EXPERIMENTAL METHODOLOGY}

\section{Compatibility studies}

FT-IR study was carried out using FT-IR (BRUKER), where the spectra of chitosan, herbal extracts, spray-dried chitosan, the physical mixtures of herbal extracts with chitosan, the physical mixtures of herbal extracts with spray-dried chitosan, and for the final spray-dried formulation were taken for the study.

\section{Design of formulation}

Drug delivery system containing herbal extracts was developed by the following methods.

\section{By cross-linking and centrifugation technique}

Chitosan solution of the concentration of $2 \mu \mathrm{g} / \mathrm{ml}$ was prepared using $1 \%$ acetic acid and stirred for $24 \mathrm{~h}$. To this polymer solution, sodium sulfate was added to separate out the particles. After stirring for $1 \mathrm{~h}$, glutaraldehyde was added to cross-link the polymer. To this solution, extracts were added $100 \mu$ geach by dissolving in ethyl acetate. The formed solution was stirred using Ultra-Turrax for $5 \mathrm{~min}$ at 2800-3000 rpm and centrifuged. The solid portion was collected, dispersed in deionized water, and kept for freeze drying at $-47^{\circ} \mathrm{C}$ for $72-96 \mathrm{~h}$.

\section{By spray-drying technique}

Chitosan solution of the concentration of $2 \mu \mathrm{g} / \mathrm{ml}$ was prepared using $1 \%$ acetic acid and stirred for $24 \mathrm{~h}$. All the three extracts were weighed $100 \mu \mathrm{g}$ each and dissolved in ethyl acetate. This solution containing herbal extracts was added to previously prepared chitosan solution. The formed solution was stirred using Ultra-Turrax for $5 \mathrm{~min}$ at 2800-3000 rpm. The resultant solution was spray dried by employing inlet air temperature of $120^{\circ} \mathrm{C}$ and a pressure of 1-1.5 psig [Fig. 1] [6-10].

\section{Evaluation}

\section{Measurement of particle size}

The particle sizes of all the formulations were determined using Olympus CX 21i Biological Microscope. The formulations were placed on the glass slide and made it to suspend using glycerin-water and placed with coverslip over the preparation and measured. The images were taken using the microscope, and the particle size was determined to obtain average minimum radius and average maximum radius.

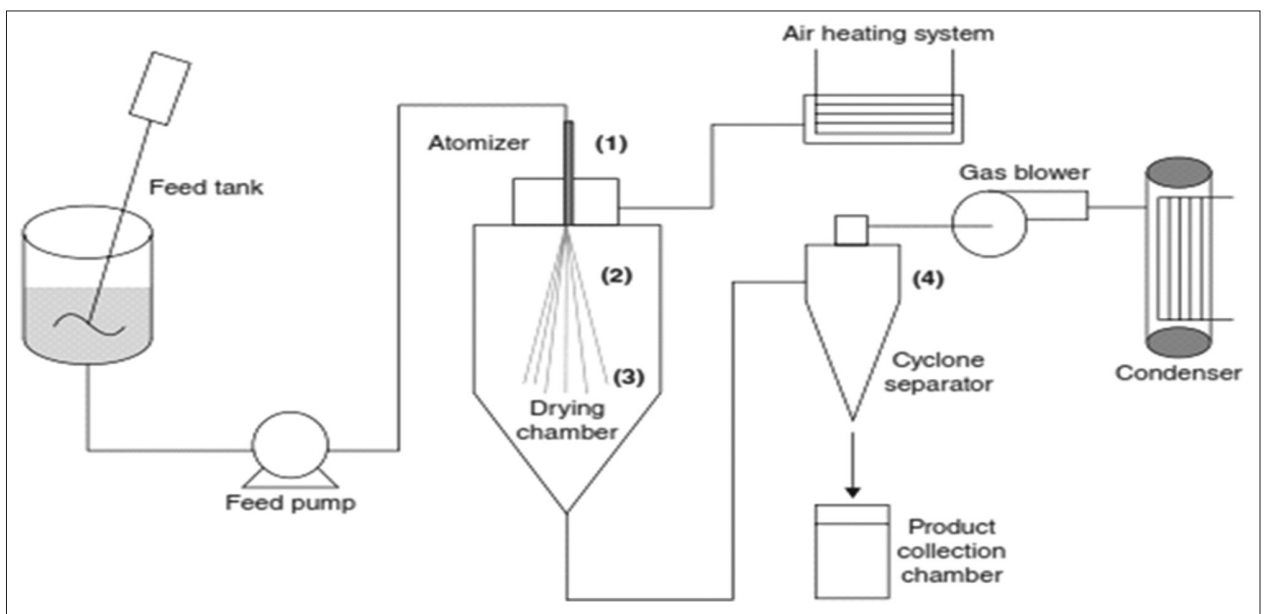

Fig. 1: Process steps of spray drying. (1) Atomization, (2) Spray-hot air contact, (3) Evaporation, (4) Separation [5]

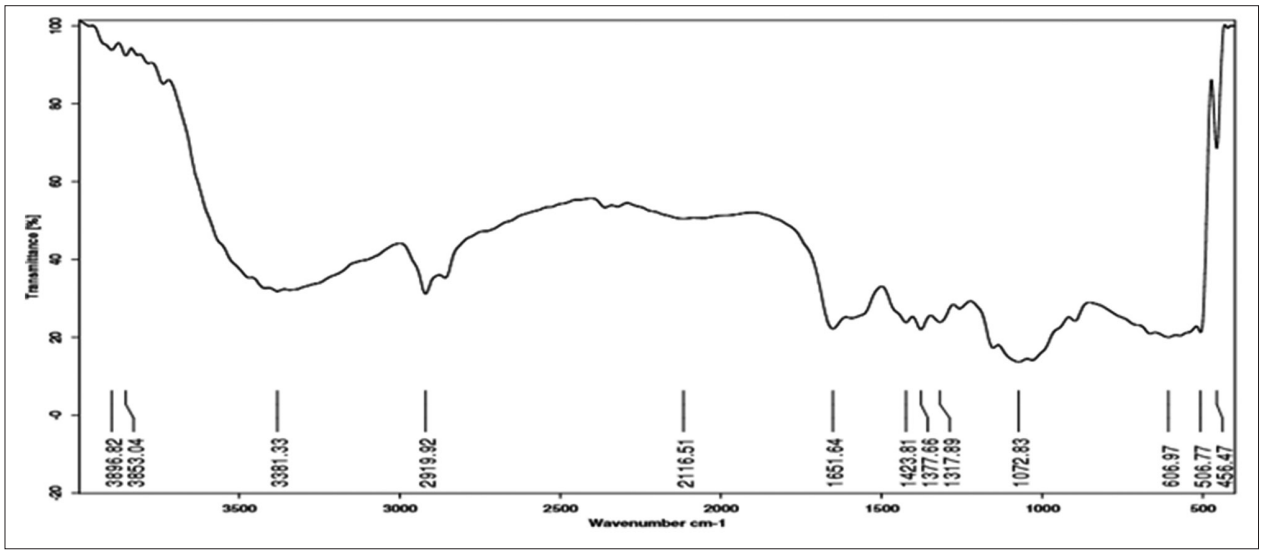

Fig. 2: FT-IR Spectrum of chitosan 


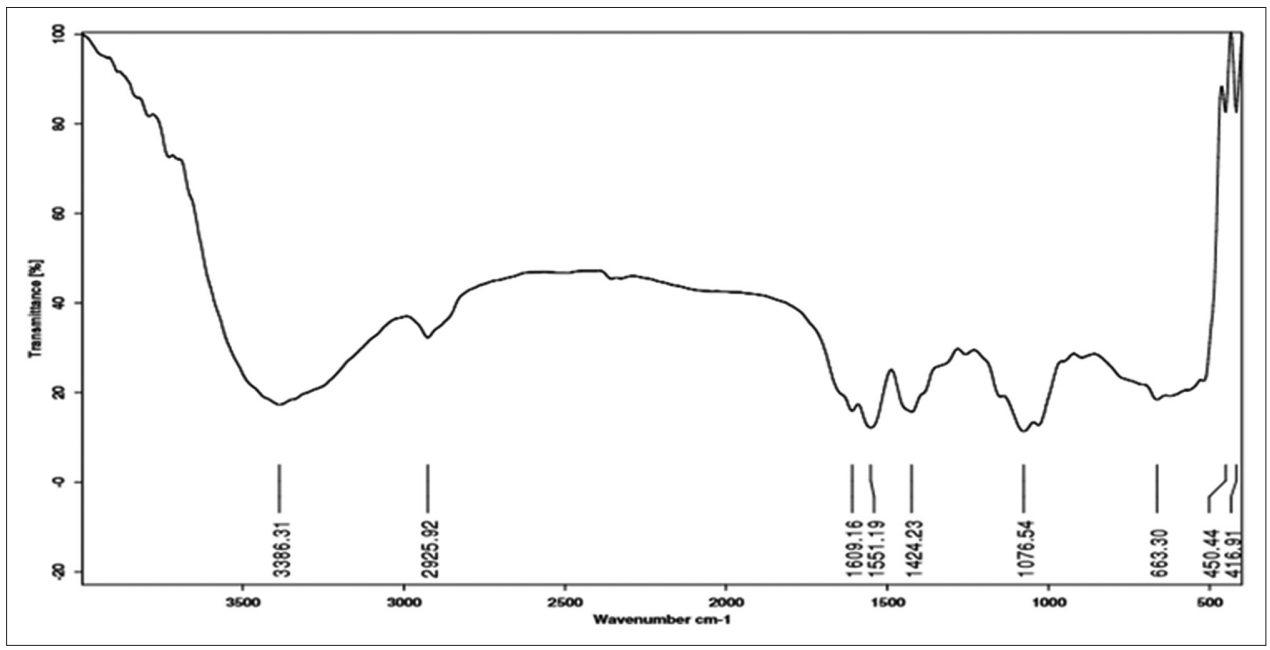

Fig. 3: FT-IR Spectrum of spray dried chitosan

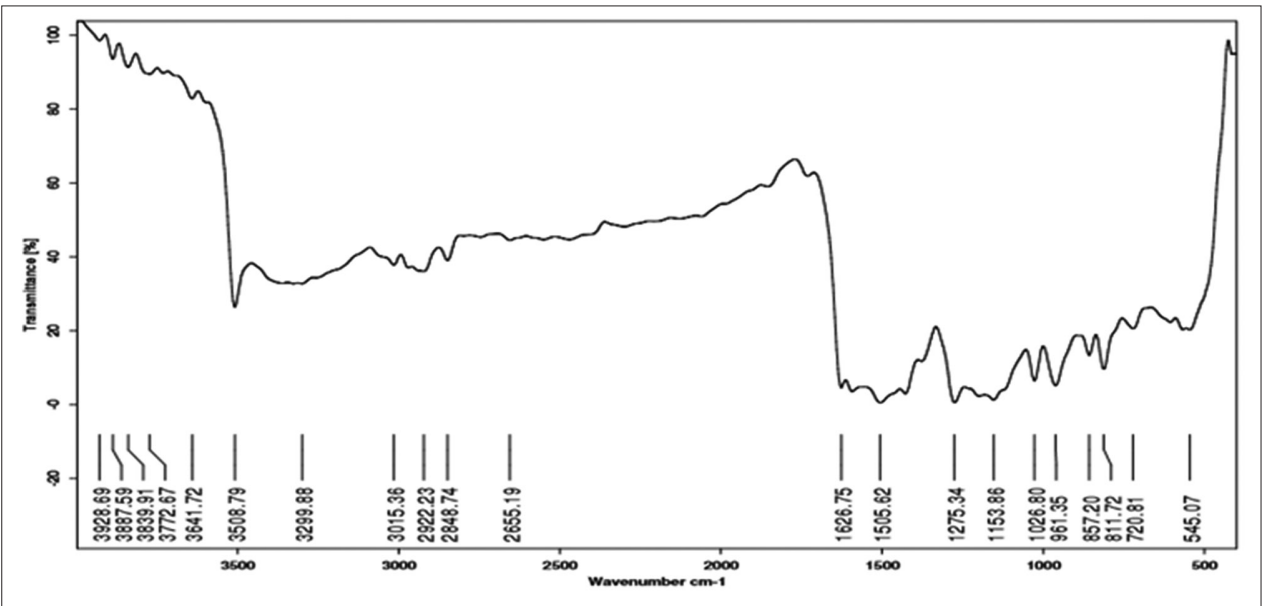

Fig. 4: FT-IR spectrum of curcumin extract

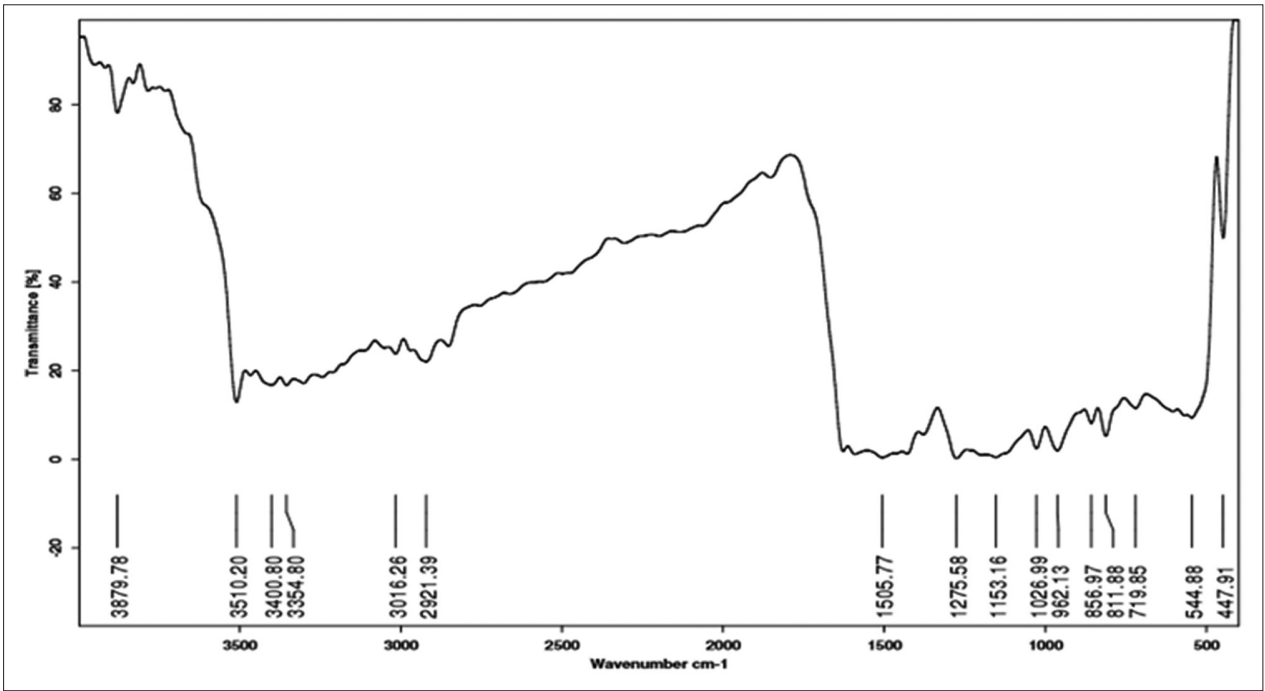

Fig. 5: FT-IR spectrum ofmixture of curcumin extract with chitosan 


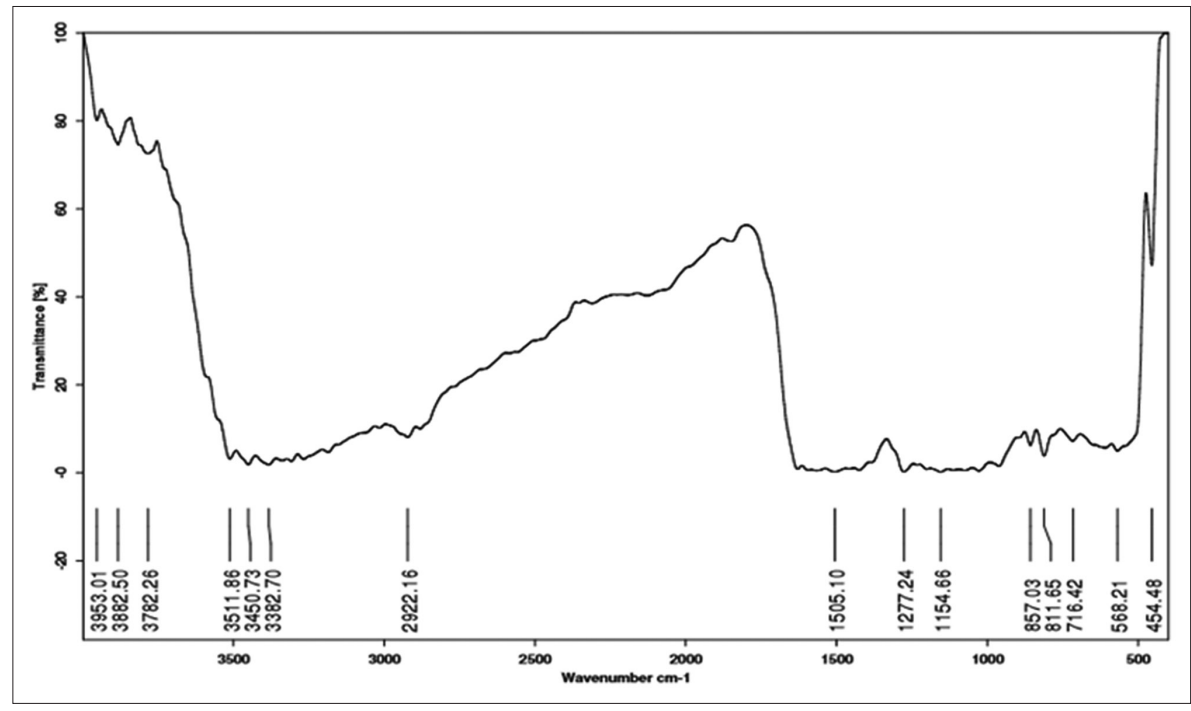

Fig. 6: FT-IR spectrum of curcumin extract with spray dried chitosan

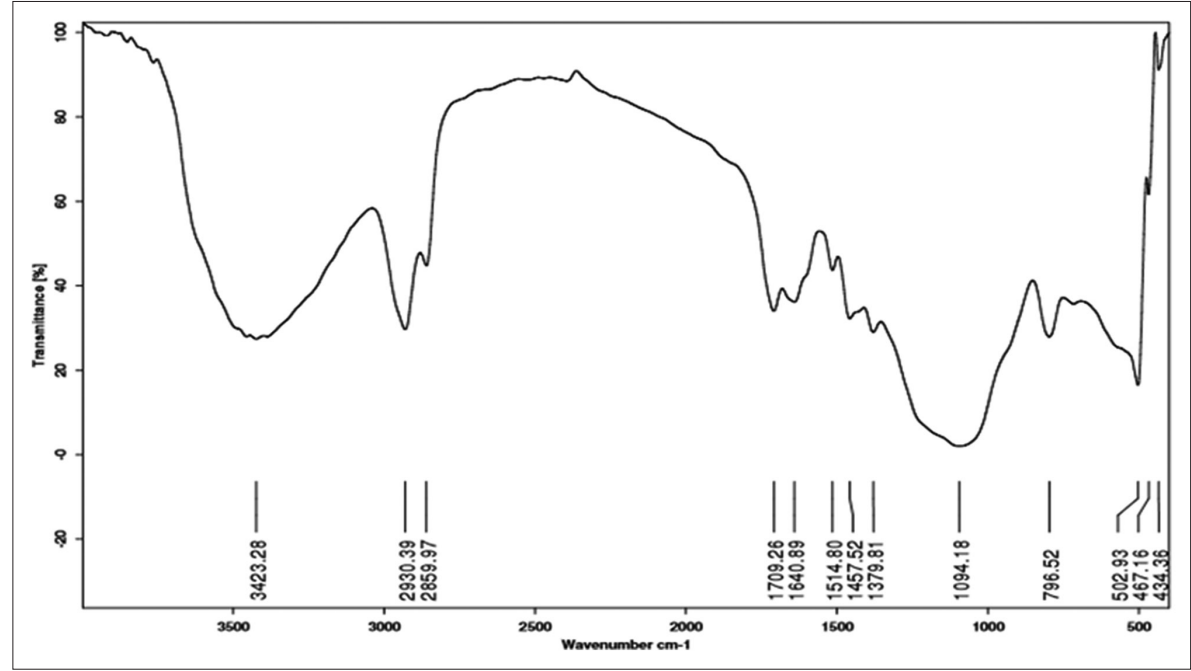

Fig. 7: FT-IR spectrum of Commiphora mukul extact

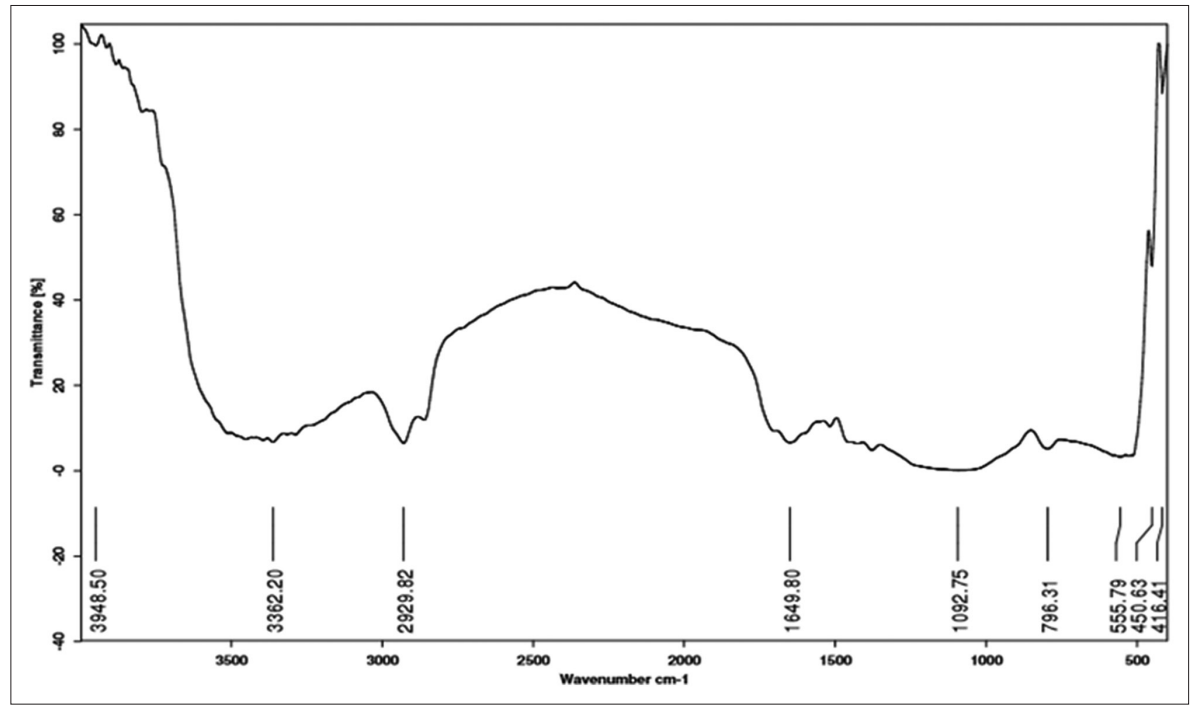

Fig. 8: FT-IR Spectrum Commiphora mukul extract with chitosan 


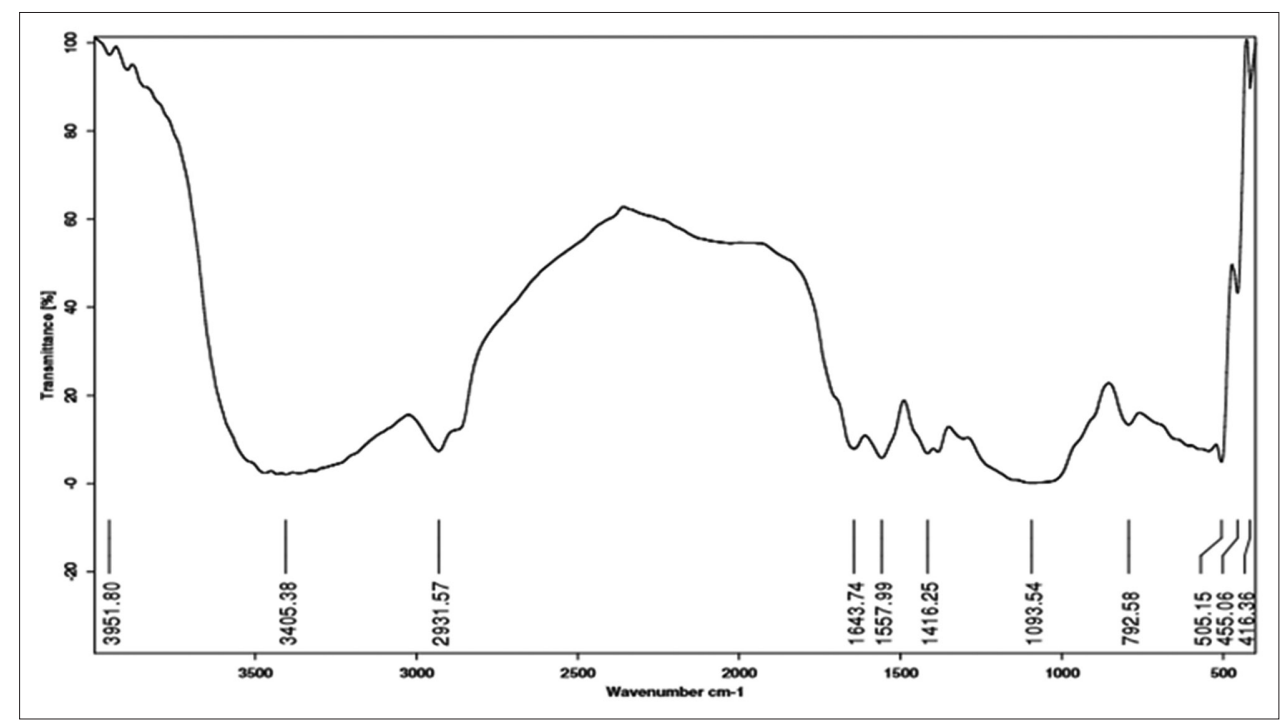

Fig. 9: FT-IR Spectrum of Commiphora mukul extract with spray-dried chitosan

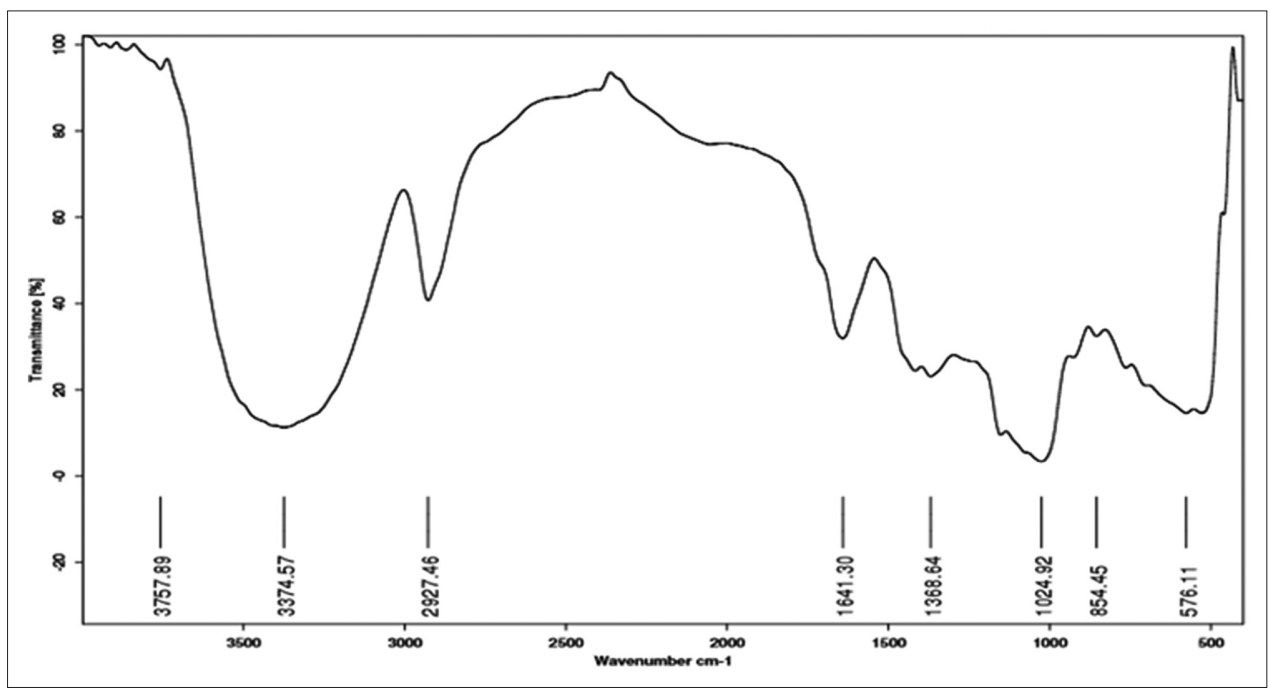

Fig. 10: FT-IR spectrum of Withania somnifera extract

\section{Surface morphology}

The surface morphology of the formulations was determined by SEM using NIKON TS100 Eclipse. The powders were fixed on a brass stub using double-sided adhesive tape and then were made electrically conductive by coating, in a vacuum with a thin layer of platinum (approximately 3-5 nm), for $100 \mathrm{~S}$ and at $30 \mathrm{~W}$. Images were taken at an excitation voltage of $10 \mathrm{kV}$ and a magnification of 5 or $15 \mathrm{k}$.

\section{In vivo studies}

SD rats of either sex (200-300 g) were maintained for 7 days in the animal house of Chalapathi Institute of Pharmaceutical Sciences, Guntur, under standard conditions temperature $\left(24 \pm 10^{\circ} \mathrm{C}\right)$, relative humidity (45-55\%), and 12:12 light:dark cycle. The animals were fed with standard rat pellet and water. The animals were allowed to acclimatize to laboratory conditions $48 \mathrm{~h}$ before the start of the experiment. Each group contains five animals.

\section{Ethical approval}

All the protocols were approved by the Institutional Animal Ethical Committee (IAEC) and conducted according to Committee for the Purpose of Control and Supervision of Experimental Animals (CPCSEA) registered no: 1048/PO/Re/S/07/CPCSEA at the Department of Pharmacology, Chalapathi Institute of Pharmaceutical Sciences, Guntur.

\section{Experimental design}

The learning and memory enhancing activity of the test formulation was investigated. Diazepam was used to induce amnesia like condition in the dose of $1 \mu \mathrm{g} / \mathrm{kg}$ administered intraperitoneal for 8 days. The test animals were randomly chosen and divided into three groups having five rats in each as follows:

- Group I: Inducing group - diazepam $(1 \mu \mathrm{g} / \mathrm{kg}$ was administered intraperitoneal for 8 days).

- Group II: Standard group - donepezil hydrochloride (2.5 $\mu \mathrm{g} / \mathrm{kg}$ was administered orally for 8 days)

- Group III: Test - test formulation containing polyherbal extracts $(10 \mu \mathrm{g} / \mathrm{kg}$ was administered orally for 8 days).

The experimental protocol was approved by the IAEC (Approval No - 17/IAEC/CLPT/2017-18.)

\section{Morris water maze (MWM)}

This technique was used to measure learning degree and spatial memory. All rats were trained in a standard MWM task. Maze consisted of large circular 


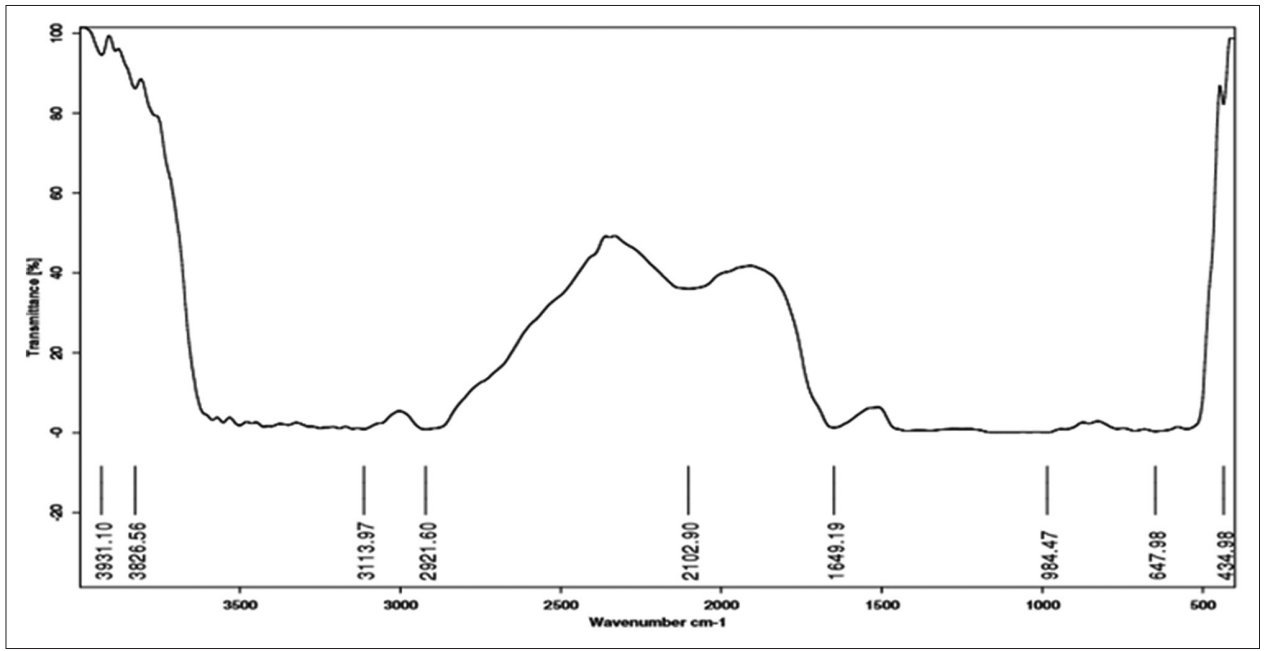

Fig. 11: FT-IR spectrum of Withania somnifera extract with chitosan

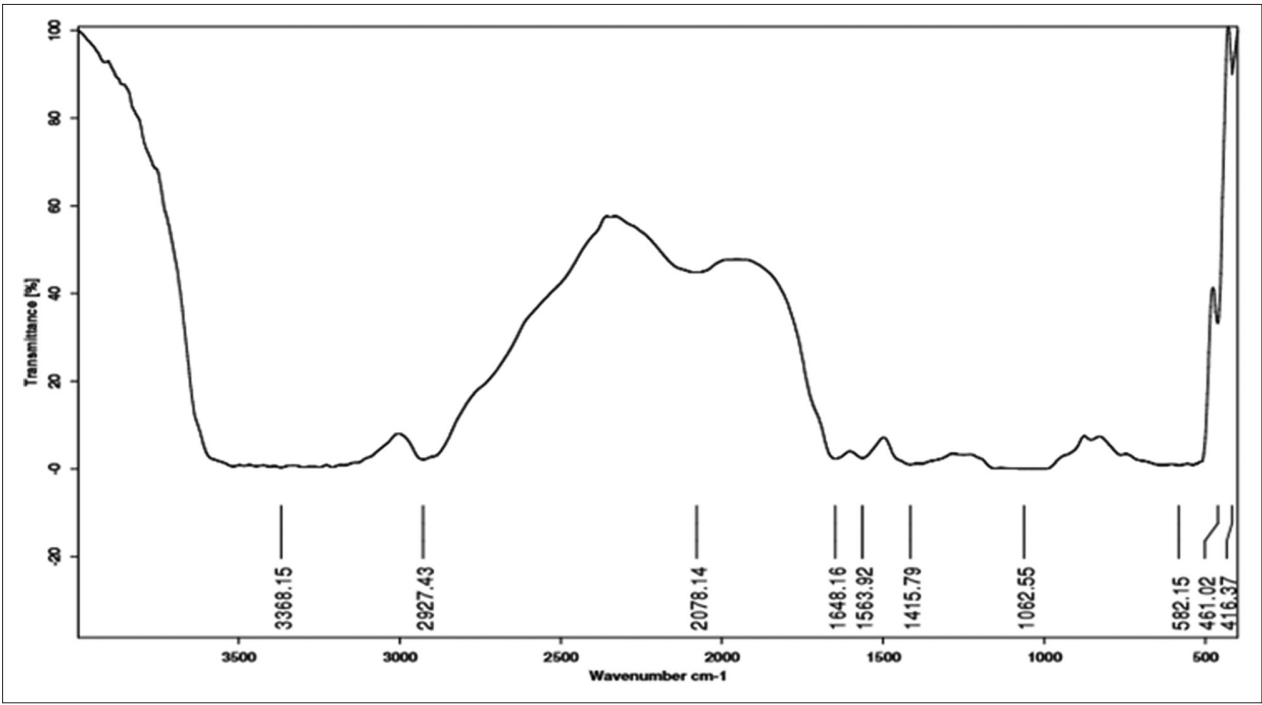

Fig. 12: FT-IR spectrum of Withania somnifera extract with spray dried chitosan

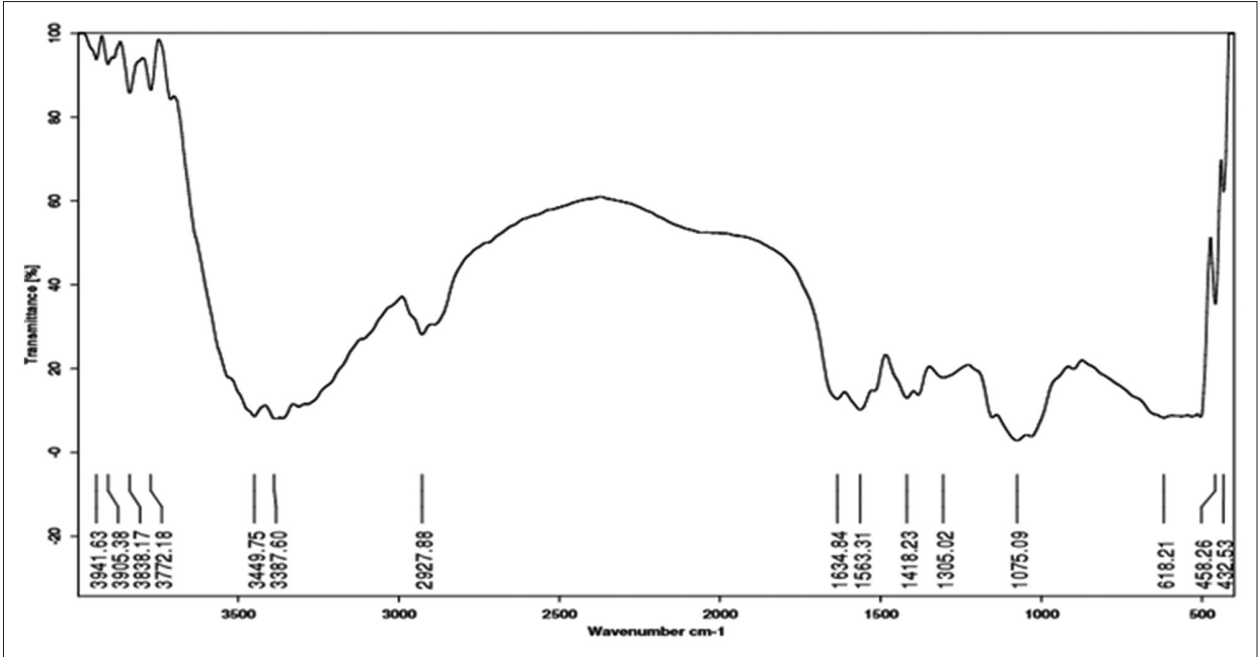

Fig. 13: FT-IR spectrum of final spray-dried formulation 
Table 1: Spray-dried formulations

\begin{tabular}{|c|c|c|c|c|c|c|c|c|c|c|c|c|c|}
\hline \multirow[t]{2}{*}{ S. No. } & \multirow[t]{2}{*}{ Ingredients } & \multicolumn{12}{|c|}{ Quantity taken in each formulation for spray drying } \\
\hline & & 1 & 2 & 3 & 4 & 5 & 6 & 7 & 8 & 9 & 10 & 11 & 12 \\
\hline 1 & Curcumin extract $95 \%(\mu \mathrm{g})$ & - & - & - & - & - & - & - & - & - & - & 100 & 100 \\
\hline 3 & Withania somnifera dry extract $(\mu \mathrm{g})$ & - & - & - & - & - & - & - & - & - & - & 100 & 100 \\
\hline 4 & Chitosan $(\mu \mathrm{g})$ & 300 & 200 & 200 & 50 & 50 & 250 & 250 & 500 & 500 & 500 & 100 & 100 \\
\hline 5 & Acetone $(\mathrm{ml})$ & 20 & 20 & 20 & 10 & 20 & - & - & - & - & - & - & - \\
\hline 6 & Liquid paraffin (ml) & - & - & - & 15 & - & - & - & - & - & - & - & - \\
\hline 7 & Span $80(\mathrm{ml})$ & - & - & - & 0.5 & - & - & - & - & - & - & - & - \\
\hline 8 & Tween $80(\mathrm{ml})$ & - & - & - & - & 0.5 & - & - & - & - & - & - & - \\
\hline 9 & Sodium sulfate $(\mu g)$ & - & - & - & - & - & 100 & - & 100 & - & - & - & 100 \\
\hline 10 & Distilled water (ml) & - & - & - & - & - & 10 & - & 10 & 250 & - & - & 10 \\
\hline 11 & Lactose (g) & - & - & - & - & - & - & - & - & 100 & - & - & - \\
\hline 12 & Glutaraldehyde (ml) & - & - & - & - & - & 2 & - & 2 & - & - & - & 2 \\
\hline 13 & $1 \%$ acetic acid (ml) & 100 & 100 & 100 & 10 & 20 & 100 & 100 & 250 & 250 & 250 & 100 & 100 \\
\hline
\end{tabular}

pool $(75 \mathrm{~cm}$ and $30 \mathrm{~cm})$ filled with water at a depth of $20 \mathrm{~cm}$. The pool was divided into four quadrants. A circular platform was placed at the center of one quadrant. The rats performed four trials period for 4 consecutive days. In the swimming trials, each individual rat was released gently into the water at a randomly chosen quadrant. The rat swam and learned how to find the hidden platform within $60 \mathrm{~S}$. After reaching the platform, rat was allowed to stay on the platform for $15 \mathrm{~S}$ and was then taken back into the cage. The rats were placed on the platform by hand for $15 \mathrm{~S}$, if they could not escape to the platform within $60 \mathrm{~S}$ by themselves, and their escape latency was accepted as $60 \mathrm{~S}$. During the intertrial intervals, animals were kept in a dry home cage for $60 \mathrm{~S}$. The time to reach the platform latency was recorded. $24 \mathrm{~h}$ after the last day of training, subjects were tested on a probe trial, during which the escape platform was removed and the time spent in the correct quadrant was measured for a $60 \mathrm{~S}$ trial.

\section{Diazepam-induced amnesia}

Diazepam $1 \mu \mathrm{g} / \mathrm{kg}$ intraperitoneal was administered to young rats and transfer latency (TL) was noted after $45 \mathrm{~min}$ of injection on the $8^{\text {th }}$ day and after $24 \mathrm{~h}$. Formulation doses and standard donepezil hydrochloride $(2.5 \mu \mathrm{g} / \mathrm{kg})$ were administered for successive 8 days. After 60 min of administration of the last dose on the $8^{\text {th }}$ day, diazepam $1 \mu \mathrm{g} / \mathrm{kg}$ intraperitoneal was administered. TL was noted after $45 \mathrm{~min}$ administration of diazepam and after $24 \mathrm{~h}$.

\section{RESULTS AND DISCUSSION}

\section{FT-IR studies}

The significant peaks that were present in chitosan were also existed in spray-dried chitosan, and similarly, the significant peaks of individual extracts and chitosan were present in spectra of physical mixtures. Final formulation spectrum showed the characteristic peaks of all the three extracts as well as polymer indicating that there were no incompatibilities between the extracts of study and the excipients [Figs. 2-13].

\section{Inference from various formulations}

In the present research study, various formulations are given in Table 1, of which formulation- 1 to formulation- 10 were not successful. Formulation-11 and 12 were successful and carried out for further investigation.

\section{Particle size}

The particle size determination was carried out using Olympus CX 21i Biological Microscope. The optical microscopy images are shown in Fig. 14. The average minimum radius and average maximum radius of each of these products were tabulated [Table 3].

\section{Surface morphology}

The SEM pictures of chitosan, spray-dried chitosan, herbal formulation by cross-linking and centrifugation, and herbal formulation by spray-
Table 2: The sequence of trials during the study period of MWM test

\begin{tabular}{llll}
\hline $\mathbf{1}^{\text {st }}$ day & $\mathbf{2}^{\text {nd }}$ day & $\mathbf{3}^{\text {rd }}$ day & $\mathbf{4}^{\text {th }}$ day \\
\hline Q1 & Q2 & Q3 & Q4 \\
Q2 & Q3 & Q4 & Q1 \\
Q3 & Q4 & Q1 & Q2 \\
Q4 & Q3 & Q2 & Q1 \\
\hline
\end{tabular}

MWM: Morris water maze

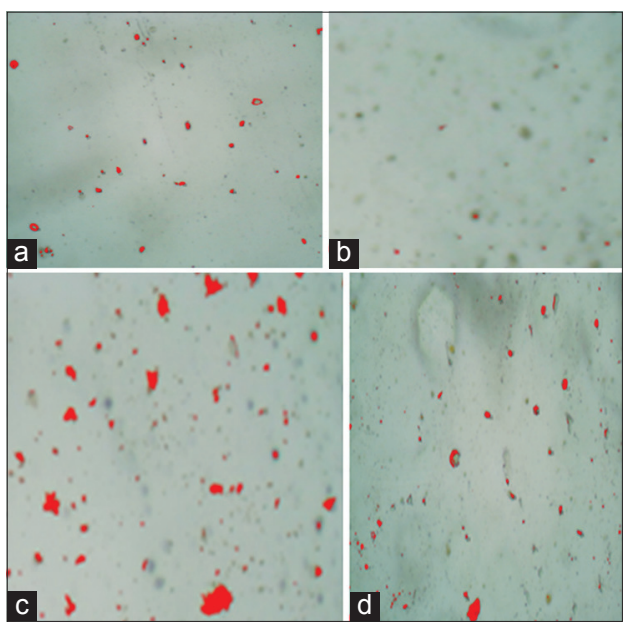

Fig. 14: Optical microscopy images of formulations. (a) Chitosan, (b) spray-dried chitosan, (c) formulation, (d) spray-dried formulation

drying method are presented in Fig. 15-18. It can be seen that the chitosan particles do not have particular shape or morphology, whereas spray-dried chitosan microspheres were spherical with wrinkles on their surface. In case of the herbal formulation prepared by crosslinking and centrifugation method, the formulation parameters induced remarkable change in the surface morphology. Herbal formulation that is made by spray-drying method, however, generated well-formed spherical particles with a smooth surface when compared to normal formulation, which generated irregularly shaped particles.

\section{In vivo studies}

MWM test

The polyherbal test formulation showed cholinesterase inhibitor mechanism at an effective dose of $10 \mu \mathrm{g} / \mathrm{kg}$ against diazepam-induced amnesia in rats. The polyherbal formulation showed comparatively 
Table 3: Particle size analysis

\begin{tabular}{lllll}
\hline S. No. & Product & Number of particles & Average minimum radius $(\boldsymbol{\mu m})$ & Average maximum radius $(\boldsymbol{\mu} \mathbf{m})$ \\
\hline 01 & Chitosan & 21 & 12.272 & 23.681 \\
02 & Spray-dried chitosan & 26 & 3.589 & 8.148 \\
03 & Formulation & 26 & 12.924 & 29.200 \\
04 & Spray-dried formulation & 26 & 2.721 & 7.612 \\
\hline
\end{tabular}

Table 4: Effect of test formulation on diazepam-induced amnesia

\begin{tabular}{lllll}
\hline S. No. & Group & Treatment & TL (in S) & \\
\cline { 3 - 5 } & & & $\mathbf{8}^{\text {th }}$ day & After 24 h (i.e., $\mathbf{9}^{\text {th }}$ day) \\
\hline 1. & I & Diazepam & $53.6 \pm 1.208$ & $56.2 \pm 1.685$ \\
2. & II & Standard+diazepam & $7.8 \pm 0.860$ & $3.2 \pm 0.663$ \\
3. & III & Test formulation+diazepam & $41 \pm 1.304$ & $39 \pm 2.469$ \\
\hline
\end{tabular}

*p-value was found to be 0.0457 using GraphPad Prism 6 software and was statistically significant

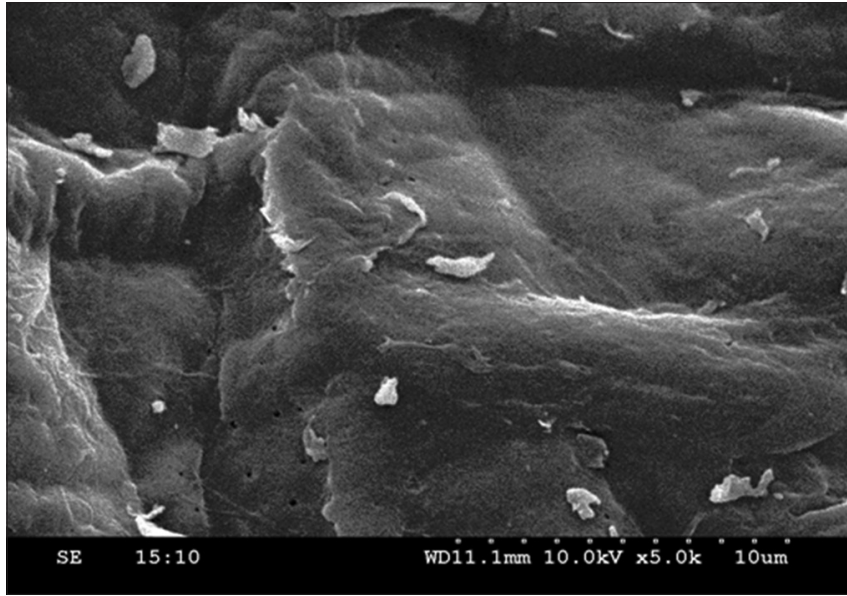

Fig. 15: Scanning electron microscopy image of chitosan

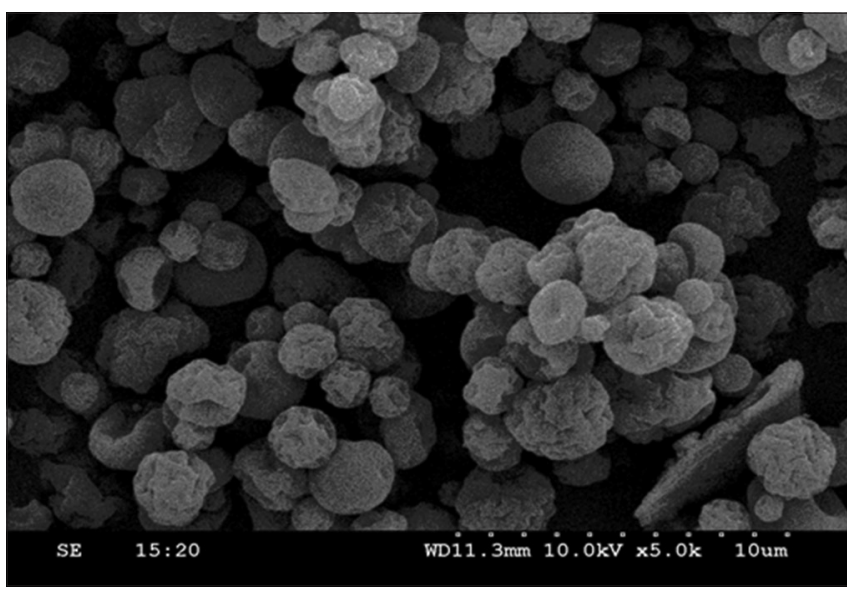

Fig. 16: Scanning electron microscopy image of spray-dried chitosan

significant effect and was measured in terms of TL in S (i.e., learning and memory activity). TL was recorded after administration of diazepam on the $8^{\text {th }}$ day and even after $24 \mathrm{~h}$ after the administration, i.e., on the $9^{\text {th }}$ day, and graphs were plotted according to the results obtained. This effect was attributed to its ability to improve the levels of the acetylcholine that is decreased in the AD [Table 4]

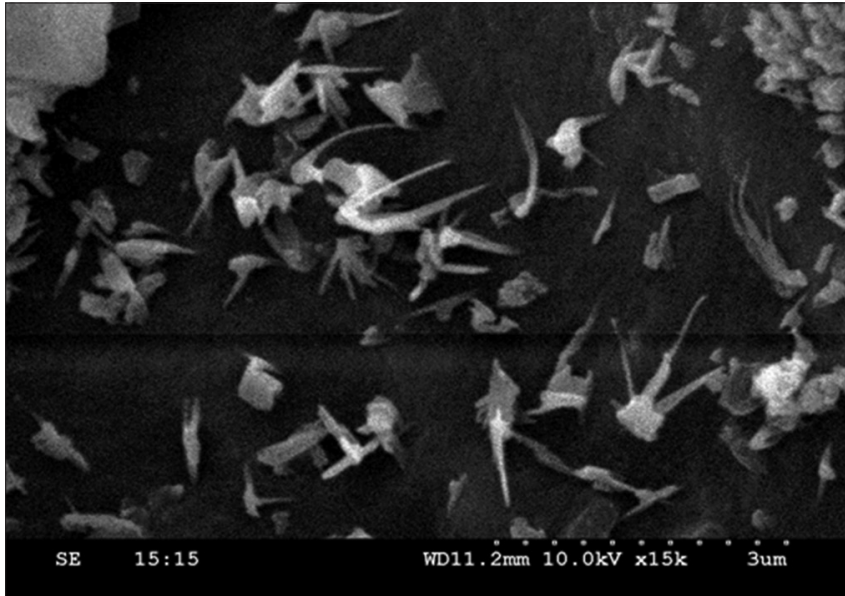

Fig. 17: Scanning electron microscopy image of normal formulation

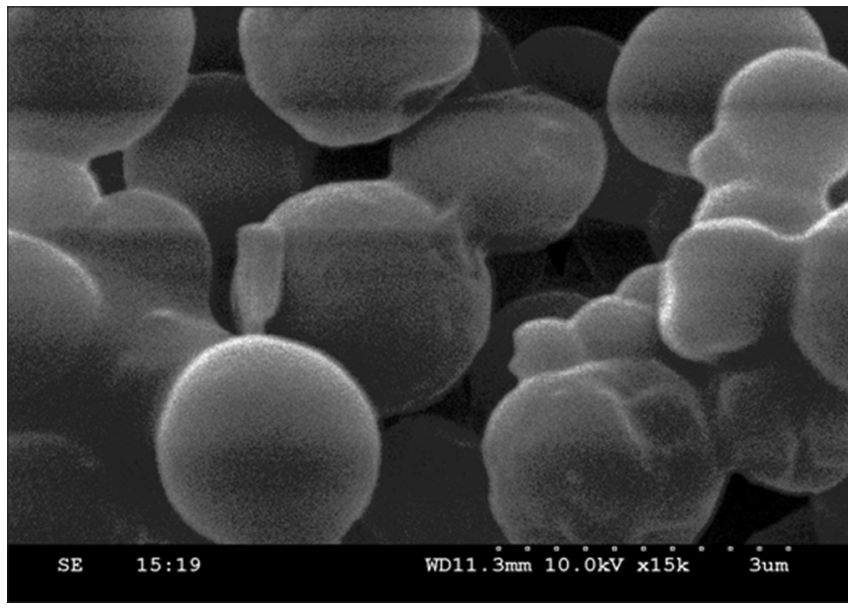

Fig. 18: Scanning electron microscopy image of spray-dried formulation

\section{CONCLUSION}

In the present research study, an attempt was made to design and develop a novel drug delivery system using herbal medicine to treat AD. FT-IR compatibility study was carried out using the selected polymer and the herbal extracts (curcumin extract, guggul extract, 


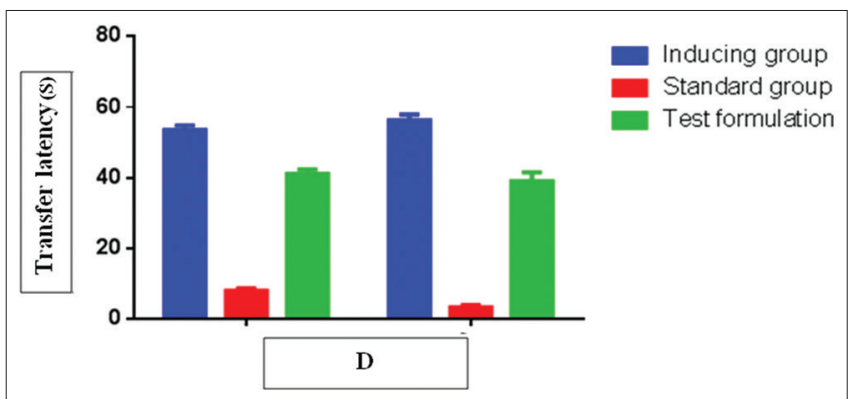

Fig. 19: Effect of test formulation on diazepam-induced amnesia **values are expressed as Mean $\pm S E, p<0.05$ versus control ( $\mathrm{n}=\mathbf{5}$ animals).

and ashwagandha extract) and a natural polymer chitosan by spray drying. The formulation was characterized for particle size analysis using Olympus CX 21i Biological Microscope, surface morphology using NIKON TS100 Eclipse, and behavioral test by MWM and was compared with the formulation that is formulated without employing spray-drying technique. From Table 3, it can be stated that the particle size varied from $12.27 \mu \mathrm{m}$ for normal chitosan to $3.59 \mu \mathrm{m}$ for spraydried chitosan. In the same way, the particle of normal formulation $(12.9 \mu \mathrm{m})$ was about 4-5 times larger than that of spray-dried formulation $(2.7 \mu \mathrm{m})$. Significant $\mathrm{p}$ value (using GraphPad Prism 6 software) was shown when the spray-dried test formulation was tested using diazepam-induced amnesia method. The TL was 41 $\mathrm{S} \pm 1.304$ on the $8^{\text {th }}$ day and $39 \mathrm{~S} \pm 2.47$ after $24 \mathrm{~h}$ of intraperitoneal administration of diazepam for the test group; it was represented in Fig. 19. Further research is going onto develop into an inhalation dosage form.

\section{AUTHORS' CONTRIBUTIONS}

Authors are extremely thankful to Chalapathi Institute of Pharmaceutical Sciences for providing necessary research facilities for successful completion of their research. Prof. Rama Rao Nadendla was working guide for this research work, has guided the spectral analysis, biochemical interpretations, and pharmacokinetic studies, and has also authored many books on medicinal and natural chemistry. Lakshmi Swapna Sai has worked on formulation using spray dryer and Ultra-Turrax and in vivo studies. Nihitha and Nagam contributed on corresponding and compilation of literature, communication of research work to the reputed and esteemed journal.

\section{ACKNOWLEDGMENTS}

The authors are thankful to Sunpure Extracts Pvt., Ltd., Delhi, for providing the extracts as gift samples, Dr. K. Suresh Babu, Principal Scientist IICT, Hyderabad. We also extend our gratitude to Principal and management of Chalapathi Institute of Pharmaceutical Sciences for providing all the required facilities for the execution of the work.

\section{CONFLICTS OF INTEREST}

The authors declare that there are no conflicts of interest regarding the publication of this paper.

\section{FUNDING STATEMENT}

The research work was supported by funding agency AICTE-RPS Scheme sanctioned with file no: 8-76/RIFD/RPS/Policy-1-2016-2017.

\section{REFERENCES}

1. Available from: https://www.nia.nih.gov/health/alzheimers

2. Rang HP, Dale MM, Ritter JM, Flower RJ. Rang and Dale's Pharmacology. $6^{\text {th }}$ ed. Edinburgh: Churchill Livingstone; 2007.

3. Available from: https://www.en.wikipedia.org/wiki/Herbalism.

4. Available from: https://www.herbs.lovetoknow.com/Advantages and Disadvantages_of_Herbal_Medicine.

5. Anandharamakrishnan C, Ishwarya SP. Spray Drying Techniques for Food Ingredient Encapsulation. $1^{\text {st }}$ ed. New Jersey: John Wiley and Sons, Ltd.; 2015 .

6. Available from: http://www.spraydrysys.com/spray-dryers/spraydrying-atomization.htm. [Last accessed on 2017 Aug 27].

7. Available from: http://www.spraydrysys.com/spray-dryers/spraydryer-design.htm. [Last accessed on 2018 Aug 27].

8. Training Papers Spray Drying. BÜCHI Labortechnik AG. Available from: https://www.static1.buchi.com/sites/default/ files/downloads/Set 3 Training Papers Spray Drying en 01. pdf?996b2db24007502 bd69c913b675467cfc63880ba

9. Available from: http://www.pharmainfo.net/book/pharmaceuticalmachines/spray-dryer. [Last accessed on 2018 Sep 21].

10. Available from: http://www.pharmapproach.com/spray-dryer. [Last accessed on 2018 Apr 17]

11. Sundur S, Ali I, Reddy AV, Satyavathi D. Evaluation of anti depressant and nootropic activity of Calophyllum inophyllum. Indo Am J Pharm Res 2015;5:2136-42.

12. Ittiyavirah SP, Ghosh R. Cognitive effects of ethanolic extract of Boerhaavia diffusa and its silver nanoparticles in ethanolic dementia model. J Phytopharmacol 2016;5:185-9.

13. Al Taani B, Khanfar M, Alsoud OA. Enhancement of the release of curcumin by the freeze drying technique using inulin and neusilin as carriers. Int J Appl Pharm 2018;10:42-8.

14. Hebbar S, Dubey A, Ravi GS, Mascarenhas SB. Studies on cross-linked chitosan hydrogel for matrix tablets of mountelukast sodium. Int J Appl Pharm 2017;9:22-9. 